\title{
Swine flu virus H1N1: a threat to human health
}

\author{
Kirti Kumari · Pooja Sharma $\cdot$ Rup Lal
}

Received: 29 April 2009 / Accepted: 5 May 2009

The sudden outburst of headlines flashing news about Influenza-A virus H1N1, causing "Swine Flu" since April this year prompts us to think yet again, what makes a virus seek alternate hosts? Is it nature's way of making humans realise of the atrocities they subject on farm animals-rearing them in confinement, fattening and killing them for mass production?

On a serious note, the capability of these smallest known parasitic microbes to become virulent by developing new strains is just amazing. The novel Influenza-A subtype H1N1 is an apt example of how rapidly viruses evolve. All influenza viruses contain two surface antigens namely-hemagglutinin $(\mathrm{H})$ and neuraminidase $(\mathrm{N})$ and the viral strains are assigned an $\mathrm{HxNx}$ nomenclature based on which forms of these two proteins are present [1]. There are $16 \mathrm{H}$ and $9 \mathrm{~N}$ subtypes known in birds, of which only H-1, 2 and 3, and N-1 and 2 are commonly found in humans [2]. The viral structure differs from strain-to-strain due to rapid genetic mutation in the genome ${ }^{1}$ and newly identified strain $\mathrm{H} 1 \mathrm{~N} 1$ responsible for swine flu in humans is the latest add-on to the list. The viral genome of H1N1 is believed to have been constituted by the reassortment of four known strains of Influenza-A virus, one endemic in humans and birds each, and two endemic in pigs (swine) [3]. This kind of quadruple reassortment is a cause of worry as the virus picks up newer genes, can develop new resistance to drugs and strike even more severely.

Human immune system combats such a viral attack with $\beta$-lymphocytes that undergo rearrangement at a high frequency and generate a repertoire of antibodies against the viral antigens. But the speed of molecular evolution in $\beta$-lymphocytes is no match for high mutation rates among

K. Kumari $\cdot$ P. Sharma $\cdot$ R. Lal $(\bowtie)$

Department of Zoology,

University of Delhi, New Delhi - 110 007, India

E-mail: ruplal@gmail.com viruses. That is, the virus could mutate again, leading to a potentially more dangerous flu outbreak, keeping researchers and pharmaceutical companies on toes to predict the virus's behaviour that would strike next season. More so, since the clinical features of influenza infection overlap with other respiratory infections, the diagnosis is often delayed due to low suspicion and the limited use of specific diagnostic tests. There is currently no vaccine against H1N1 and seasonal influenza vaccines available do not offer any protection against it. Contrary to these beliefs, some virologists are of the view that the current situation is not problematic since H1N1 lacks PB1-F2, a protein which has been linked to virulence [4].

Researchers are digging past data for clues about the seasonality and geography of pandemic influenza flu. There is a good amount of information available on the four pandemics that have occurred since 1890, and they all followed different seasonal patterns [4]. It is vital to predict the path and pace of the virus causing this outbreak so that decisions about mitigation strategies, antiviral therapy and vaccination can be pursued.

Although the threat seems to have subsided now but making predictions about H1N1's next move is not easy, as is aptly said, "There's nothing more predictable about flu than its unpredictability [4]."

\section{References}

1. Mishail T (2007) Viruses versus humans: molecular evolution at work. Manila, Star Science (Philippine Headline News Online)

2. Lynch JP and Walsh EE (2007) Influenza: evolving strategies in treatment and prevention. Semin Respir Crit Care Med 28: 144-158

3. MacKenzie D (2009) Deadly new flu virus in US and Mexico may go pandemic. New Scientist (News Update)

4. Cohen J (2009) Past pandemics provide mixed clues to H1N1's next moves. Science 324:996-997 